\title{
Glatte Summen
}

\author{
Die Seite für Kinder
}

Sebastian Lutz und Brigitte Lutz-Westphal

Wie wahrscheinlich ist es, beim Einkaufen im Supermarkt einen glatten Euro-Betrag zu bezahlen? Hängt es auch von der Anzahl der gekauften Artikel ab?

Beim obersten Bon waren es immerhin 108 Artikel beim Einkauf für ein großes Fest.
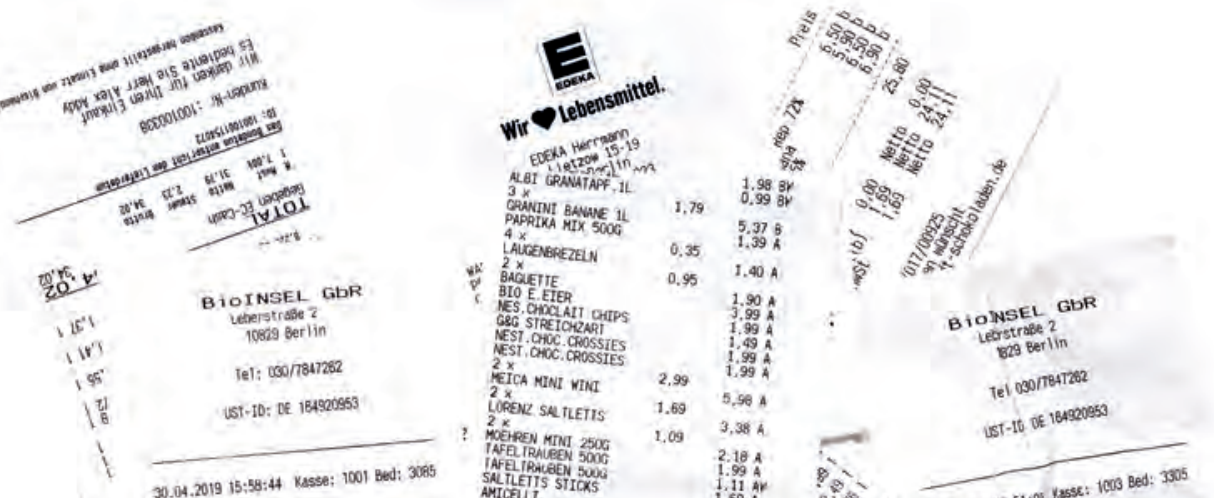

LOPERR SAL FLETIS $\quad 1.69 \quad 5.90 \mathrm{~A}$
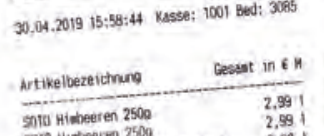

Sontu Himeeren 2500

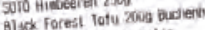
airuesol sild nativ extra Yofu vanille sood Yơu vasillie 5000 thiffel diverse :orte

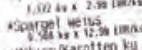
molievkaratten ky. steigcliopitgrens bran

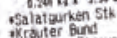
virater bund

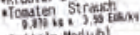
buttein Medigh
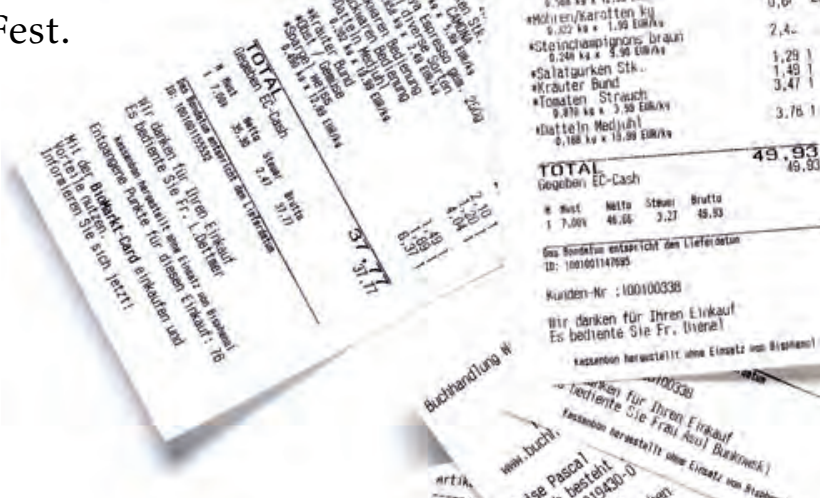

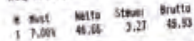

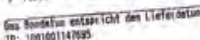

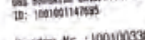

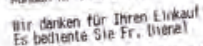

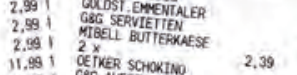

$\begin{array}{ll}2.99 & 1 \\ 21 & 2\end{array}$ 2.491 G8G ALS SOH TRFF

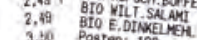
sis sive

1,39
$0,6,64$ SUMME
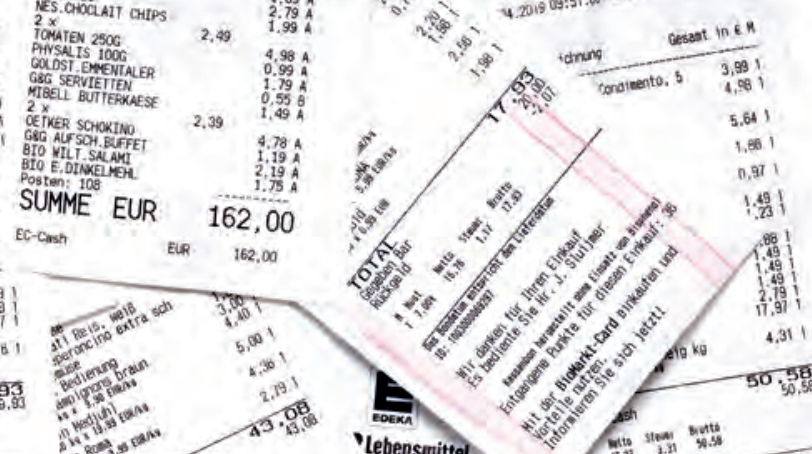

$$
\text { , }
$$
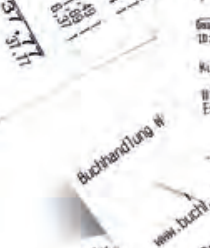

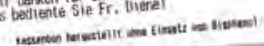

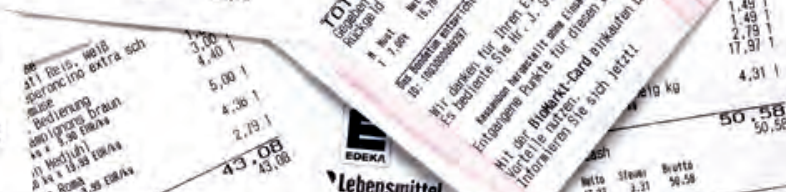

列

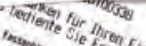
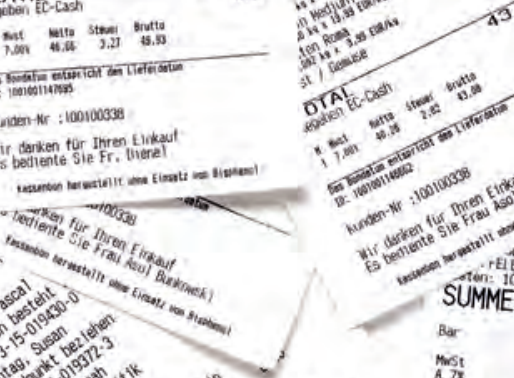

鲜兽

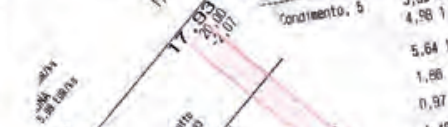

